\title{
Adult Central Nervous System Choriocarcinoma
}

National Cancer Institute

\section{Source}

National Cancer Institute. Adult Central Nervous System Choriocarcinoma. NCI

Thesaurus. Code C5793.

A choriocarcinoma affecting the central nervous system and occurring in adulthood. 